\title{
A ofensiva do SEBRAE sobre o Ensino Médio
}

\author{
The SEBRAE offensive on high school
}

\section{La ofensiva del SEBRAE en la escuela secundaria}

\author{
Magalhães, Ramon Mendes da Costa ${ }^{1}$ (Carangola, MG, Brasil) \\ ORCID ID: https://orcid.org/0000-0002-8535-4929 \\ Lamosa, Rodrigo de Azevedo Cruz ${ }^{2}$ (Nova Iguaçu, RJ, Brasil) \\ ORCID ID: https://orcid.org/0000-0002-7183-9589
}

\begin{abstract}
Resumo
Esse artigo tem por objetivo analisar a atuação do SEBRAE e sua influência sobre as instituições educacionais na conjuntura em que esta organização se torna o principal difusor da "educação empreendedora" em todo o território nacional no âmbito do Ensino Médio. Em meio a pandemia do COVID-19 em 2020, o SEBRAE lançou um documento intitulado "Empreendedorismo no currículo escolar do ensino médio", com vista a se colocar a "disposição" como "parceiro" de instituições públicas e privadas no desenvolvimento do empreendedorismo. A estratégia de pesquisa utilizada foi a análise de conteúdo, por meio do qual foi possível compreender criticamente as formulações presentes no documento produzido pelo SEBRAE. O processo de análise não foi produzido de maneira estática e sequencial, há um movimento constante entre os documentos, as hipóteses e objetivos, para se chegar à sua formulação final. Buscamos ir além do conteúdo apresentado no documento, ir além da aparência, pois, interessa o conteúdo latente, a essência, o sentido e mediações que se encontram por trás da aparência imediata. Concluímos, então, que o documento analisado tem uma intencionalidade explicita de colocar o SEBRAE com o principal "parceiro" para desenvolver o empreendedorismo no ensino médio das instituições educacionais do país, por meio do projeto de "educação empreendedora", difundindo entre gestores, professores e estudantes uma determinada forma de ser, agir e pensar na sociedade.
\end{abstract}

Palavras-chave: Empreendedorismo. Educação. Ensino Médio.

\begin{abstract}
This article aims to analyze the performance of SEBRAE and its influence on educational institutions in the context in which this organization becomes the main diffuser of "entrepreneurial education" throughout the national territory in the scope of high school. In the midst of the COVID-19 pandemic in 2020, SEBRAE launched a document entitled "Entrepreneurship in the high school curriculum", with a view to placing the "disposition" as a "partner" of public and private institutions in the development of entrepreneurship. The research strategy used was content analysis, through which it was possible to critically understand the formulations present in the document produced by SEBRAE. The analysis process was not produced in a static and sequential way, there is a constant movement between the documents, hypotheses and objectives, to reach their final formulation. We seek to go beyond appearance, therefore, interests the latent content, essence, meaning and mediations that lie behind the immediate appearance. We conclude, then, that the analyzed document has an explicit intention to place SEBRAE with the main "partner" to develop entrepreneurship in high school educational institutions in the country, through the project of "entrepreneurial education", spreading among managers, teachers and students a certain way of being, acting and thinking about society.
\end{abstract}

Keywords: Entrepreneurship. Education. High school.

\section{Resumen}

Este artículo tiene como objetivo analizar el desempeño de SEBRAE y su influencia en las instituciones educativas en el contexto en el que esta organización se convierte en el principal difusor de la "educación emprendedora" en todo el territorio nacional en el ámbito de la escuela secundaria. En medio de la pandemia COVID-19 en 2020, SEBRAE puso en marcha un documento titulado

\footnotetext{
1 Departamento de Educação, Linguística e Letras (DELL). Universidade do Estado de Minas Gerais - Unidade Carangola.ramon.magalhaes@uemg.br

2 Departamento de Educação e Sociedade (DES). Programa de Pós-Graduação em Educação, Contextos Contemporâneos e Demandas Populares (PPGEduc). Universidade Federal Rural do Rio de Janeiro. rodrigo1281@yahoo.com.br
} 
"Emprendimiento en el currículo de bachillerato", con el fin de situar la "disposición" como "socio" de las instituciones públicas y privadas en el desarrollo del emprendimiento. La estrategia de investigación utilizada fue el análisis de contenidos, a través del cual fue posible comprender críticamente las formulaciones presentes en el documento producido por SEBRAE. El proceso de análisis no se produjo de manera estática y secuencial, hay un movimiento constante entre los documentos, hipótesis y objetivos, para llegar a su formulación final. Buscamos ir más allá del contenido presentado en el documento, ir más allá de la apariencia, porque interesa el contenido latente, la esencia, el significado y las mediaciones que están detrás de la apariencia inmediata. Concluimos, a continuación, que el documento analizado tiene una intención explícita de colocar a SEBRAE con el principal "socio" para desarrollar el emprendimiento en las instituciones educativas de secundaria del país, a través del proyecto de "educación emprendedora", difundiendo entre directivos, profesores y alumnos una cierta forma de ser, actuando y pensando en la sociedad.

Palavras-Clave: Emprendimiento. Educación. escuela secundaria.

\section{Introdução}

Em meio a pandemia do COVID-19 em 2020, o Serviço Brasileiro de Apoio às Micro e Pequenas Empresas (SEBRAE) lançou um documento intitulado "Empreendedorismo no currículo escolar do ensino médio" (SEBRAE, 2020), com vista a se colocar a "disposição" como o principal "parceiro"3 de instituições públicas e privadas no desenvolvimento do empreendedorismo. Esse artigo tem por objetivo analisar a atuação do SEBRAE e sua influência sobre as instituições educacionais na conjuntura em que esta organização se torna o principal difusor da "educação empreendedora" em todo o território nacional no âmbito do Ensino Médio.

O empreendedorismo se tornou uns dos eixos estruturante do Ensino Médio, a partir de 2017, tendo sido atualizado pelas Diretrizes Curriculares Nacionais do Ensino Médio (DCNEM) em 2018 (BRASIL, 2018a) para dar sustentação a Base Nacional Comum Curricular do Ensino Médio (BNCCEM), homologada no mesmo ano (BRASIL, 2018b). Entretanto, não é de hoje que o SEBRAE atua na disseminação da cultura empreendedora para se formar empreendedores, com foco:

[...] no fortalecimento do empreendedorismo e na aceleração do processo de formalização da economia por meio de parcerias com os setores público e privado, programas de capacitação, acesso ao crédito e à inovação, estímulo ao associativismo, feiras e rodadas de negócios (SEBRAE, s/d1, online).

Segundo Castro (2019), o empreendedorismo assumiu um papel de destaque na atuação do SEBRAE, entrando de forma "sistemática na pauta do SEBRAE, justamente quando ocorreu o crescimento do desemprego estrutural no

\footnotetext{
3 Utilizamos o termo "parceiro" ou "parceria" entre "aspas", visto que acreditamos, assim como Martins, Souza e Pina (2020, p. 10) que "o termo parceria é insuficiente para qualificar o conteúdo histórico da relação públicoprivada". Para os autores a relação entre o público e privado formam uma unidade dialética contraditória, visto que ambos possuem características, fundamentos, interesses e finalidades históricas divergentes e até mesmo inconciliáveis, mas que na realidade concreta não se anulam. Assim sendo, concordamos com os autores que "a relação entre eles é engendrada por uma profunda contradição e não pela convergência como o termo parceria sugere (MARTINS; SOUZA; PINA, 2020, p. 10)".
} 
Esse processo, que se intensifica a partir dos anos 2000, é nitidamente perceptível através da realização de feiras, prêmios, programas e capacitações que tem no tema do empreendedorismo seu eixo central. Essas ações educativas - que no primeiro momento tinha como público alvo os pequenos e médios empresários já constituídos - vão se expandir de tal forma até alcançar o ambiente escolar (CASTRO, 2019, p.43).

Em relação aos projetos de educação para o empreendedorismo que são desenvolvidos nas escolas, o SEBRAE tem grande relevância, pois desde o final do século XX ele atua junto as instituições públicas capacitando e desenvolvendo projetos para a educação empreendedora. Para Dias (2018) "os projetos e narrativas da agência têm buscado atingir diferentes públicos com vistas a educar os sujeitos para uma "nova ordem" capitalista (p.412)".

A "educação empreendedora" proposta pelo SEBRAE busca imergir os professores no ambiente e na cultura empreendedora para posteriormente atuarem na difusão desta cultura dentro do espaço escolar, trazendo exemplos de empreendedores, da vida cotidiana e de sucesso, para despertar o espirito empreendedor nos alunos. Esse discurso reproduz os pilares da educação propostos no "relatório Jacques Delors" (DELORS, 1998), acrescidos do "apreender a empreender" que foi introduzido alguns anos depois pelo Projeto Regional de Educação para a América Latina e o Caribe (PREALC, 2004).

Com vista a sua atuação dentro da sociedade na promoção e formação para o empreendedorismo, compreendemos, a partir da teoria do Estado, formulada por Gramsci (2014), que o SEBRAE se configura como um Aparelho Privado de Hegemonia (APH) da classe burguesa. Na concepção gramsciana, os APHs, segundo Martins (2009, p. 19) "são organizações políticas e culturais de diferentes tipos, localizados na sociedade, responsáveis por atuar de modos e espaços distintos, visando a conquista, a consolidação e a manutenção do consenso e torno de um projeto societal".

Para Gramsci (2014), há dentro da sociedade civil uma gama de iniciativas e atividades de outros aparelhos privados, que constituem o aparelho de hegemonia política e cultural do Estado capitalista, do bloco no poder. As atividades do Estado capitalista atingem a todos os campos da atividade da vida cotidiana, não só a esfera política, mediatizados pelas ações dos aparelhos privados de Estado (POULANTZAS, 2015) e por seus intelectuais orgânicos. Nesse sentido, os aparelhos privados atuam 
Programa de Pós-graduação em Educação, Universidade Federal do Ceará

Fortaleza-CE-Brasil

como organizadores da vontade coletiva e do consenso geral, organizando diferentes interesses e projetos de sociabilidade dentro do Estado ampliado, que se colocam em disputa na sociedade civil.

O SEBRAE busca, enquanto tarefa educativa e formativa dentro do Estado ampliado, e, principalmente, no âmbito da sociedade civil, criar novos e mais elevados tipos de sociabilidades, adequando a sociedade, classes e frações de classe que a compõe, às necessidades da estrutura e da superestrutura do modo de produção capitalista, produzindo novos tipos de trabalhadores. Para produzir um consenso social em torno do projeto societal capitalista, seja junto as micro e pequenas empresas ou na disseminação da cultura empreendedora, o SEBRAE atua na produção de valores morais e condutas, para engendrar uma ordem social alinhada aos seus interesses de classe, bem como criar uma cultura de coesão social em torno desses interesses, de modo a legitimar suas formas de intervenção e atuação junto as sociedade política e civil, empresas e escolas, frações de classe e trabalhadores individuais.

Neste sentido, o SEBRAE, por meio de suas ações de assessoramento, capacitação, produção de pesquisas e documentos, e materiais de educação empreendedora, busca estabelecer padrões de sociabilidade, comportamentos e pensamento que promovam a adesão espontânea e voluntária das classes sociais, em especial da classe trabalhadora, para consolidação da hegemonia burguesa, seja na esfera da produção, do trabalho, ou no plano da cultura e da educação. Com isso, busca disciplinar a classe trabalhadora tanto na vida produtiva como social, a fim de consolidar a ideologia burguesa permeada de interesses materiais e imateriais para universalizar uma consciência social e de vida burguesa.

\section{Método}

Para alcançar nosso objetivo, tomaremos como método, o materialismo histórico-dialético, de modo à atingir um conhecimento que permita avançar para além das aparências fenomênicas, na progressiva e histórica compreensão da realidade (KOSIK, 1976).

A pesquisa dialética pretende explicitar como se dá a relação de causalidade, do fenômeno com a essência, do todo com as partes, dentro da realidade social concreta e real (GAMBOA, 2000). O método dialético se constitui como "o 
Programa de Pós-graduação em Educação, Universidade Federal do Ceará

Fortaleza-CE-Brasil

pensamento crítico que tem intenção de compreender a coisa em si e compreender adequadamente a realidade na sua essência, para além de esquemas abstratos da realidade e suas representações (MAGALHÃES, 2019, p.87)".

Para isso, a estratégia a ser utilizada foi a análise de conteúdo, para que possamos compreender criticamente as formulações presentes no documento produzido pelo SEBRAE. O processo de análise não foi produzido de maneira estática e sequencial, há um movimento constante entre os documentos, as hipóteses e objetivos, para se chegar à sua formulação final. Buscamos ir além do conteúdo apresentado no documento, ir além da aparência, pois, interessa o conteúdo latente, a essência, o sentido e mediações que se encontra por trás da aparência imediata.

O materialismo histórico dialético como método de análise da realidade nos possibilita, a partir de seus pressupostos, fundamentos e categorias, analisar as mediações dentro dos processos históricos em qual se encontra a atuação e a ofensiva do SEBRAE para disseminação da cultura empreendedora dentro da totalidade dos fatos e contradições que as envolvem, no movimento da aparência à essência, para se chegar realidade concreta, que não é estática, mas que se encontra em constante transformação. Além disso, o materialismo histórico dialético nos permite superar a forma fetichizada que se encontram os fenômenos educacionais e revelar suas possíveis intenções na formação dos indivíduos e na consolidação de políticas educacionais.

Apresentados nosso objetivo e nosso método de análise, passamos a análise do documento "Empreendedorismo no currículo escolar do ensino médio" produzido pelo SEBRAE em 2020 (SEBRAE, 2020).

\section{Resultado}

O documento "Empreendedorismo no currículo escolar do ensino médio" (SEBRAE, 2020) se organiza em quatorze seções/temáticas compreendendo desde a apresentação do documento até a missão do SEBRAE em desenvolver o empreendedorismo.

Logo na apresentação, o SEBRAE advoga que para enfrentar os novos tempos do mercado de trabalho são necessárias soluções inovadoras para que os professores possam enfrentar os novos desafios, e entre essas inovações, estaria a educação empreendedora. Segundo o SEBRAE (2020, p. 5), "a educação 
Programa de Pós-graduação em Educação, Universidade Federal do Ceará

Fortaleza-CE-Brasil

empreendedora é uma das ferramentas fundamentais para orientar os estudantes a se posicionarem diante dos desafios impostos por essa nova realidade, tornando-os protagonistas de suas trajetórias profissionais". Essa formação, atenderia a metas estabelecidas para o desenvolvimento sustentável de 2030, que visa "aumentar o número de jovens e adultos que tenham as competências necessárias para o trabalho decente e o empreendedorismo (p.5)".

Para sustentar o desenvolvimento da educação empreendedora, que foi reconhecida com a aprovação da BNCC, o SEBRAE, utiliza em diversos momentos desse documento, um discurso pautado na sua experiência com o empreendedorismo para se colocar a disposição para a implementação da educação empreendedora nos currículos. Segundo o SEBRAE, os "mais de 25 anos de experiência e envolvimento no desenvolvimento de soluções de empreendedorismo para a educação formal, é hoje reconhecida como uma das maiores referências do país nessa área (SEBRAE, 2020, p. 5)". No documento, o SEBRAE ressalta que dispõe de um "Centro SEBRAE de Referência em Educação Empreendedora" (CER) e como ele pode ajudar os estados e municípios, assim como seus professores, a colocar em prática a educação empreendedora e o desenvolvimento de um projeto de vida no Ensino Médio, através de materiais, dicas e orientações. Isso fica evidente na seguinte formulação do SEBRAE:

O Sebrae quer somar forças frente a este desafio e, para tal, coloca à disposição das Secretarias Estaduais de Educação vasto material orientativo, além da grande expertise acumulada na organização. De tal modo, Excelentíssimo governadores e Excelentíssimos secretários de educação, contem conosco para essa caminhada (SEBRAE, 2020, p. 7).

Para o SEBRAE, essa relação possibilitaria que os estados e municípios incorporassem em seus currículos:

[...] o desenvolvimento de competências empreendedoras como criatividade, inovação, organização, visão de futuro, assunção de riscos, resiliência e curiosidade científica espera-se que os estudantes mobilizem conhecimentos, habilidades, atitudes e valores para resolver demandas complexas relacionadas às suas escolhas pessoais e profissionais, como também favorecer a sua inclusão social e empregabilidade (SEBRAE, 2020, p.5).

Nota-se que essa disponibilidade do SEBRAE para a implementação da educação empreendedora e sua vinculação a formação dos estudantes ao desenvolvimento da cultura empreendedora, no sentido de resolver os problemas da vida social e produtiva, apesar de não situá-los, está ligada a lógica liberal e neoliberal, 
Programa de Pós-graduação em Educação, Universidade Federal do Ceará

Fortaleza-CE-Brasil

sendo que para que isso ocorra, serão necessárias mudanças individuais na forma de ser, agir e pensar a sociedade por parte dos estudantes e a contrapartida dos estados e municípios na disponibilização de recursos do fundo púbico para o SEBRAE.

Outro ponto de destaque no documento, é o desenvolvimento do "Projeto de Vida" dos estudantes, que segundo o SEBRAE seria "a tradução da educação integral exigida na Base Nacional Comum Curricular (BNCC) (SEBRAE, 2020, p.6)". Esse projeto seria a chave para que os alunos compreendessem a si mesmos e o mundo, bem como, a forma de efetivar seus sonhos, desejos e interesses através de ações concretas. Neste sentido, a uma forte vinculação do discurso de que através de ações individuais, esforço e resiliência é possível, em qualquer contexto, se realizar pessoalmente e profissionalmente.

Em nossa análise, o SEBRAE desconsidera as condições materiais de existências, a classe social e a materialidade das condições de educação da classe trabalhadora no país, em prol de um discurso sedutor e mistificador, de que as oportunidades de sucesso estão abertas a todos. Com isso, a proposta do SEBRAE hipoteca o futuro dos alunos, seus sonhos e seus projetos de vida, bem "constringe sua vontade, inteligência, sua consciência em formação a mover-se por um caminho cuja meta seja prefixada (GRAMSCI, 2011, p. 58)", meta essa pautada pelo empreendedorismo.

Para o SEBRAE, os conteúdos da educação empreendedora, como reflexões e atividades de autoconhecimento, exemplos de empreendedores para inspiração, resolução de problemas de forma colaborativa e promoção da diversidade, ajudariam os alunos "a refletir sobre os seus sonhos e a utilizar ferramentas para criar e organizar ideias que os tornem realidade (SEBRAE, 2020, p.6)". Chamamos atenção que os conteúdos apontados, não são exclusividade da educação empreendedora, mas a ênfase que é dada a esses conteúdos dentro da cultura empreendedora, bem como, as bases históricas e conceituais que sustentam o empreendedorismo são determinantes para compreender qual cidadão e trabalhador espera-se formar para atender as demandas da sociabilidade burguesa e da reprodução do capital.

$\mathrm{Na}$ seção "Resumo Executivo" o SEBRAE reforça sua intenção de "colaborar", através do sistema de "parcerias", para adaptação e o enfrentamento dos novos desafios da educação, cintando as consequências da pandemia do COVID-19, como um desses desafios. Em seguida, o SEBRAE aponta que esse momento 
Programa de Pós-graduação em Educação, Universidade Federal do Ceará

Fortaleza-CE-Brasil

aparece também como um espaço de oportunidades para a educação, seja pública ou privada, se colocando a disposição "para colaborar na elaboração dos currículos do Novo Ensino Médio, apoiando os gestores da educação, nas diferentes esferas da administração, para darem esse passo tão importante na formação dos jovens brasileiros (SEBRAE, 2020, p.9)".

No plano da aparência, essa colaboração se apresenta como positiva, mas indo à essência das concepções que sustentam a educação empreendedora, notamos que essa colaboração busca a manutenção da hegemonia burguesa dentro da educação e da sociedade civil, visto que o SEBRAE se configura como um APH da classe burguesa que atua na disseminação da cultura empreendedora tão necessária para o enfrentamento da crise estrutural do capital, exacerbada pela pandemia do COVID-19, na qual o desemprego estrutural, a responsabilização, o trabalho precário e informal, são condições estruturantes do modo de produção capitalista em seu estágio atual.

$\mathrm{Na}$ seção "Base Nacional Comum Curricular (BNCC) - Marco do Empreendedorismo na Educação" o SEBRAE busca enfatizar que a versão final da BNCC, que consta o ensino médio, favorece ainda mais a cultura para o empreendedorismo e amplia a sua capacidade de desenvolver competências, ao mobilizar conhecimentos, habilidades, atitudes e valores para resolver demandas da vida social e produtiva, provocada pela 4 Revolução Industrial, bem como atenderia as expectativas dos jovens. Segundo 0 documento, as competências empreendedoras fundamentais para a inclusão social e a empregabilidade seriam: "criatividade, inovação, organização, planejamento, responsabilidade, liderança, colaboração, visão de futuro, assunção de riscos, resiliência e curiosidade científica (SEBRAE, 2020, p. 10)".

O SEBRAE reforça que na base nacional o empreendedorismo é visto como uma oportunidade para realização de intervenções durante toda a vida dos alunos na sociedade, podendo ser desenvolvido em espaços de negócios, como empreendedorismo social, intraempreendedorismo e empreendedorismo tecnológico, bem como de outras formas. Além disso, ele vai atuar em conjunto com as competências cognitivas e socioemocionais para intervir no meio social, promovendo o voluntariado e as iniciativas particulares (SEBRAE, 2020). A partir dessas formulações em relação a BNCC, constatamos que o SEBRAE tem a intenção de levar 
Programa de Pós-graduação em Educação, Universidade Federal do Ceará

Fortaleza-CE-Brasil

a cultura empreendedora para todos os espaços da vida social e produtiva, formando um sujeito dotado da cultura empreendedora, bem como de competências para se empregar ou se manter empregado, atendendo assim a noção de empregabilidade, bem como, para criar seu próprio emprego, visto que não a posto de trabalhos para todos.

Seguindo com a discussão, o SEBRAE ressalta que dentro das escolas de ensino médio, a "educação empreendedora" utilizaria de projetos e outras experiências empreendedoras para resolver problemas atuais, tanto individuais e da coletividade, sendo para isso necessário o engajamento dos professores para aprender junto com os alunos a cultura empreendedora e o uso de "metodologias presenciais e remotas de modo a garantir aos estudantes o desenvolvimento de competências cognitivas, atitudinais e práticas (SEBRAE, 2020, p.12)”. Neste sentido, - SEBRAE busca enfatizar a sua experiência com metodologias ativas e com 0 empreendedorismo, de modo a levar as instituições públicas e privadas a criarem uma relação com eles, como podemos ver em tela.

Crescem, portanto, as oportunidades de parcerias com instituições que utilizam esse conceito há mais tempo, como é o caso do Sebrae, cuja metodologia de desenvolvimento de processos formativos para atender o seu público-alvo sempre se pautou na centralidade do educando e no uso de metodologias ativas, desenvolvendo nos empreendedores a autonomia para estar à frente dos seus negócios tomando decisões inteligentes e sustentáveis (SEBRAE, 2020, p. 12).

Constatamos que nesse documento o SEBRAE se coloca como se fosse um serviço a ser adquirido pelas instituições. Neste sentido, o SEBRAE se lança ao mercado como um importante detentor de conteúdos e metodologias que o "novo ensino médio" necessita. Para isso ele apresenta como se daria sua ação na futura relação estabelecida com as instituições de ensino:

Logo, a participação do Sebrae se faz por meio da capacitação dos educadores de todos os níveis de ensino, com as metodologias e formações presenciais e remotas do Programa Nacional de Educação Empreendedora (PNEE) e com a utilização dos conteúdos postos na plataforma do CER Centro Sebrae de Referência em Educação Empreendedora. E não só isso, existe ainda a possibilidade de atendimento direto aos estudantes por meio da oferta de produtos presenciais ou remotos e de outros objetos de aprendizagem (SEBRAE, 2020, p.12)".

Nota-se como a educação se torna uma mercadoria, e não um direito público de acesso à cultura humana e aos conhecimentos científicos socialmente produzidos pela humanidade no decorrer do processo histórico. Para o SEBRAE (2020, p.14), a "educação empreendedora" para se efetivar de forma equânime na 
Programa de Pós-graduação em Educação, Universidade Federal do Ceará

Fortaleza-CE-Brasil

educação brasileira, "deverá ser fortemente pautado pela formação adequada dos gestores e dos professores, pela disseminação de métodos e tecnologias educacionais mais atrativas e pela revisão do modelo de avaliação do desempenho escolar". Toda essa relação do SEBRAE com as instituições de educação teria sido viabilizada pela BNCC, visto que ao fomentar o empreendedorismo na educação básica, o SEBRAE pode atuar na formação dos gestores, professores e alunos, para que adotem "uma postura aberta, flexível e de respeito aos diferentes pontos de partida de cada localidade (SEBRAE, 2020, p.15)", e acrescentaríamos, a visão do ponto de vista individual, como se cada indivíduo dentro das relações sociais desiguais entre as classes sociais em disputa, pudesse ser empreendedores, partindo de sua realidade material e social, devido as "oportunidades" que o mercado oferece a eles.

Assim sendo, o discurso defendido pelo SEBRAE, é de que a "educação empreendedora" despertaria "atitudes e fomenta escolhas conscientes desde a infância, passando pela juventude e atrela ações coerentes e transformadoras ao longo da vida, tanto para a realização pessoal quanto para crescimento da economia do país (SEBRAE, 2020, p.13)", totalmente alinhado as concepções econômicas e comportamentais, as quais o empreendedorismo se pauta. Nos contrapomos a esse discurso, visto que a "educação empreendedora" proposta pelo SEBRAE, tendo um caráter interessado (representa os interesses da classe burguesa), acaba por retirar dos alunos as reais possibilidades de "realizar sua própria individualidade do melhor modo possível e, por isso, do modo mais produtivo para eles mesmos e para a coletividade (GRAMSCI, 2011, p. 58)", restando aos alunos da classe trabalhadora uma vida de incertezas e instabilidade.

Na seção "A pandemia e o papel do Sebrae", são elencadas 6 formas que o SEBRAE pode contribuir para a educação brasileira, tendo por base o conceito de Mundo VULCA ${ }^{4}$, para que as pessoas desenvolvam resiliência para enfrentar esse momento. A primeira ação proposta seria "realização de oficinas de competências socioemocionais para professores e gestores escolares (SEBRAE, 2020, p.16, grifos do original)", demostrando a importância que essas competências adquirem nos projetos atuais do SEBRAE. A segunda, terceira e quarta proposições tem foco na

${ }^{4}$ A sigla VUCA significa: VOLATILITY (volatilidade), UNCERTAINTY (incerteza), COMPLEXITY (complexidade) e AMBIGUITY (ambiguidade). 
Programa de Pós-graduação em Educação, Universidade Federal do Ceará

Fortaleza-CE-Brasil

gestão escolar, sendo que a segunda proposta se relaciona "a apoiar o gestor através de um curso de técnicas de comunicação aplicadas ao contexto escolar para estabelecer rotinas de diálogo com a comunidade (SEBRAE, 2020, p. 17, grifos do original)", bem como a disponibilização de uma cartilha para os gestores em seu portal. A terceira complementa a segunda, ao oferecer aos gestores "formações sobre comunicação, engajamento e modos de atendimento às comunidades escolares (SEBRAE, 2020, p. 17, grifos do original)". A quarta proposição busca oferecer também aos gestores "formações sobre liderança para gestores escolares, focando em uma gestão cada vez mais humana e voltada para resultados (SEBRAE, 2020, p.17, grifos do original)", oferecendo também uma cartilha com fundamentos teóricos e práticos com foco na excelência da gestão. Nota-se a preocupação do SEBRAE em levar através das suas formações suas concepções e com isso tornar os gestores, que tem contado direto com a comunidade escolar, disseminadores da cultura empreendedora, que segundo o discurso propagado possibilitaria que alunos, professores e gestores lidem com as incertezas e instabilidades aguçadas, diga-se de passagem, pela pandemia.

A quinta proposição também tem foco na gestão escolar, mas agora com a intenção de preparar a escola para o retorno as aulas, pautados no discurso que nos momentos "de grande dificuldade, geralmente afloram ideias criativas e inovadoras. Olhar os problemas como oportunidade para fazer mais e melhor é uma boa maneira de enfrentamento à crise provocada pela Covid-19 (SEBRAE, 2020, p. 17)". Para isso eles oferecem três cartilhas, produzidas a partir de referenciais da UNESCO e OMS: a) Protocolo de Retomada - Serviços Educacionais - Escolas; b) Protocolo de Retomada - Serviços Educacionais - Cursos Livres; c) Protocolo de Retomada Transporte Escolar (SEBRAE, 2020, p.17)". Ressaltam ainda que essas cartilhas estão sendo usadas pelo Conselho Nacional de Secretários da Educação (CONSED), para nortear os protocolos das redes estaduais de educação.

Nota-se que o SEBRAE busca legitimar suas proposições utilizando de um discurso de "poder" baseado nas recomendações de organismos transnacionais, como se esses organismos fossem isentos dos interesses da burguesia na formação da classe trabalhadora para atender as demandas do capital. Para finalizar, o SEBRAE informa que "está organizando um programa de atendimento com foco na Gestão Financeira, que conta com a produção de conteúdos para serem 
Programa de Pós-graduação em Educação, Universidade Federal do Ceará

Fortaleza-CE-Brasil

disponibilizados aos gestores em diferentes formatos: cartilha, webinar, live, seminário online, dentre outros (SEBRAE, 2020, p. 18)". Constatamos que essa última proposição, associada as anteriores, tem a intencionalidade de racionalizar 0 processo de gestão das escolas, situando-as numa visão gerencialista da educação, no qual o objetivo final são os resultados, como esboçado na proposição quatro pelo próprio SEBRAE.

Um fato importante a se ressaltar, é o destaque dado ao Instituto Ayrton Senna (IAS), no final da última proposição, para que juntos, "em regime de colaboração, contribuir para o desenvolvimento de competências socioemocionais de professores e gestores escolares (SEBRAE, 2020, p. 18)". Isso reforça, a relação das competências empreendedoras e socioemocionais na formação dos indivíduos, sejam eles gestores, professores ou alunos, de forma que se produza um novo tipo de trabalhador para atender as demandas do capital, tanto no âmbito social como produtivo

O SEBRAE encerra suas proposições reafirmando acreditar que essas soluções propostas, também se aplicam nos calendários regulares, reforçando assim sua intenção de estabelecer uma relação com as instituições públicas e privadas para além da pandemia, se tornando um grande organizador da gestão e dos processos escolares, tendo por base a cultura empreendedora e as competências socioemocionais.

Na seção "Mundo do Trabalho" o SEBRAE procura sustentar a defesa da importância de se desenvolver as competências empreendedoras e socioemocionais através de elementos retirados de uma pesquisa por eles realizados em 2019, intitulada "o Empreendedorismo do Amanhã", na qual eles objetivaram "identificar características e competências desejadas para os empreendedores de sucesso nos próximos 5 a 10 anos (SEBRAE, 2020, p. 19)". Se incluírem essas competências na escola, os pesquisados e o SEBRAE acreditam que teríamos de um modo geral, pessoas mais bem preparadas, com liderança, funcionários com atitudes empreendedoras e futuros empreendedores para se adaptarem ao mundo do trabalho. Sendo que, na visão dos entrevistados "os quesitos comportamentais são mais importantes que os técnicos (SEBRAE, 2020, p. 20)", o que reforça nossa tese, de que o interesse da classe burguesa é formar um sujeito que tenha uma nova forma de ser, agir e pensar, pautadas na cultura empreendedora, que molde o 
Programa de Pós-graduação em Educação, Universidade Federal do Ceará

Fortaleza-CE-Brasil

comportamento dos indivíduos para se adaptarem e aceitarem as incertezas, instabilidade e responsabilidades das suas condições materiais de existência.

Na seção "Projeto de Vida", o SEBRAE reafirma que esse projeto é a tradução da educação integral. Essa é a perspectiva da BNCC e do próprio SEBRAE, que se pauta no liberalismo, no neoliberalismo e nos interesses do empresariado na educação, como evidenciado na dissertação de Pires (2019) que analisou a influência empresarial na política curricular brasileira, em especial Movimento pela Base Nacional Comum. A autora conclui que, a classe empresarial tem o intuído e desejo que, "ao invés de possibilitar o diálogo crítico com a realidade, tendo como télos a emancipação humana, a escola pública se afirme como instância de formação unilateral para a empregabilidade e para a cidadania restrita (PIRES, 2019, p. 254)". Neste sentido, somente com uma formação emancipatória que poderíamos falar em educação integral, educação essa que desenvolva todas as potencialidades humanas em suas múltiplas dimensões e que possibilite a apropriação dos conhecimentos científicos, filosóficos e artísticos produzidos pelo homem dentro do processo histórico de desenvolvimento da humanidade.

Observa-se que o SEBRAE busca com o discurso do desenvolvimento de projetos de vida, que cada indivíduo produza para si mesmo "oportunidades" para se ter sucesso, se responsabilizando por seu sucesso ou fracasso, pois foi o próprio indivíduo que construiu o seu projeto de vida, desta forma, não teria o "direito" de questionar o resultado se ele der errado. No entanto, compreendemos que as condições materiais de existências dos sujeitos sociais são produtos do modo de produção capitalista e da sociabilidade burguesa, sendo assim, se torna contraditório, responsabilizar o sujeito por seu projeto de vida, visto que antes de tudo, sua vida é condicionada pela sua condição de classe dentro das relações sociais de produção.

O SEBRAE acrescenta que alguns aspectos devem estar contemplados no Projeto de Vida a ser desenvolvido pelas escolas públicas e privadas: Reflexão e atividades de autoconhecimento; exemplos e inspirações; resolução colaborativa de problemas, e; promover a diversidade. Todos esses aspectos são a base da educação empreendedora, que se pauta na formação do espirito empreendedor a partir de seus sonhos, na busca de inspirações em empreendedores de sucesso, na resolução de problemas cotidianos de forma individual e coletiva, o que relativiza a situações específicas de aprendizagem. Além disso, ao utilizar do discurso da promoção da 
Programa de Pós-graduação em Educação, Universidade Federal do Ceará

Fortaleza-CE-Brasil

diversidade para "exercitar a capacidade de argumentação e de negociação, tão importantes para a vida profissional e pessoal (SEBRAE, 2020, p. 23)", o SEBRAE limita sua discussão a respeitar a diversidade em relação a aspectos econômicos e relativos ao gerenciamento de negócios, e não de respeito a pluralidade cultural da sociedade.

Na seção "Educação Empreendedora", o SEBRAE busca recuperar a história que ele tem com o desenvolvimento da educação empreendedora para se colocar como o "parceiro ideal" para as instituições públicas e privadas que buscam desenvolver as competências empreendedoras desde a escola, e não só atuando junto as micro e pequenas empresas.

Na seção "Benchmarking de Empreendedorismo: Comissão Europeia" o SEBRAE tem a intenção de trazer elementos da cultura empreendedora de outros continentes e países, em especial do continente europeu, reforçando as justificativas em níveis individuais, organizacionais e sociais, tendo efeitos: na criação de emprego; no sucesso econômico; na globalização, inovação e renovação; no contentamento, compromisso e criatividade, e; nos desafios sociais. Nota-se que os aspectos econômicos e comportamentais são a base para a adoção da cultura empreendedora nas instituições de ensino, pautadas na noção de competências. Outro importante aspecto a ser observado nesta seção, é que o SEBRAE desconsidera as diferenças econômicas, culturais e sociais entre o Brasil e os países europeus de capitalismo central, negando a condição de capitalismo periférico que interfere diretamente na divisão internacional do trabalho e no tipo de empreendedorismo realizado no Brasil, que na sua maioria se trata de um empreendedorismo por necessidade devido ao desemprego estrutural e a precarização do trabalho.

Na seção "Desafios para Implantação de Empreendedorismo nas Escolas" o SEBRAE apresenta a finalidade da educação empreendedora, que seria "encontrar soluções que impactem e transformem a vida das pessoas e da comunidade (SEBRAE, 2020, p. 31)". Além disso, apresenta seu foco tanto para o Ensino Fundamental e Médio, que são voltados para o desenvolvimento das competências socioemocionais trabalhadas pelas metodologias da educação empreendedora, a fim de formar alunos que desenvolvam sonhos e desejos, enfrentem as incertezas e assumam riscos em seus empreendimentos e em seus projetos de vida. Para o SEBRAE (2020, p. 31-32): 
A trajetória escolar passa a conectar, assim, percepções individuais com a construção das dimensões cidadã e profissional do estudante. No início dessas conexões, está o Projeto de Vida, ponto de partida para toda estratégia. O estudante a todo momento testará o seu autoconhecimento, identificando prazeres e qualidades a ponto de se sentir autoconfiante para tomar decisões. A autogestão surge em seguida como uma capacidade a ser desenvolvida, de modo a refletir com seus conhecimentos sobre o mundo físico, social e cultural sobre possibilidades existentes para a resolução dos problemas e, de forma empática, realizar um pensamento crítico que leve à criatividade. O planejamento, por sua vez, trabalhará a perseverança em ambientes cooperativos, com a determinação de construir um valor ao final do processo em que é preciso foco, comunicação, colaboração e resiliência (grifos do original).

Nota-se que os aspectos individuais são os mais enfatizados nesse trecho em tela, evidenciando a responsabilização, comportamentos adequados e persistentes, para enfrentar e se adaptar as demandas produtivas e sociais do capital. Em relação ao ensino médio, o SEBRAE acrescenta que "é importante o desenvolvimento de competências empreendedoras para a geração de negócios (SEBRAE, 2020, p. 32)", relacionando o ensino médio diretamente ao mercado de trabalho. Neste sentido, o empreendedorismo se apresenta, na visão do capital, enquanto uma solução para a diminuição dos postos de trabalhos decorrentes das mudanças causadas pela $4^{\circ}$ Revolução Industrial, e não por uma crise estrutural do capital.

Essas consequências decorrentes da $4^{\circ}$ Revolução Industrial, nas formulações do SEBRAE, levará muitos trabalhadores a serem donos seus próprios negócios, seja por necessidade (modelo que predomina no Brasil) ou por oportunidades. Assim, os futuros trabalhadores dotados de competências empreendedoras, possibilitada pela inserção do eixo estruturante do empreendedorismo no ensino médio, e que se apresentam também nos eixos, "processos criativos, e mediação e intervenção sociocultural" poderão empreender em negócios ou em tecnologia, ou mesmo se tornarem empreendedores sociais.

Na seção "Organização do Conteúdo de Empreendedorismo pelo Sebrae", o SEBRAE é enfático em se colocar como uma instituição com a maior "expertise" em relação ao empreendedorismo e a educação empreendedora, como podemos ver em tela:

É inquestionável o fato de que o Sebrae é uma instituição que detém grande conhecimento sobre o conteúdo de Empreendedorismo e que a sua experiência vai além do atendimento a empresários de pequenos negócios. A ação do Sebrae se estende às escolas, onde se encontram os potenciais empreendedores (SEBRAE, 2020, p. 34). 


\section{Em seguida, deixa claro seu interesse "de reforçar e ampliar o seu} atendimento, especialmente agora que o Empreendedorismo figura na BNCC do Novo Ensino Médio como um dos eixos estruturantes para compor os itinerários formativos do currículo da juventude brasileira (SEBRAE, 2020, p.34)", atuando de formar mais incisiva nas escolas, através das relações estabelecidas com as escolas públicas e particulares, para formação de gestores, professores e alunos.

Posteriormente, apresentam que, os conteúdos de empreendedorismo do SEBRAE organizam-se em torno de um fluxo de quatro etapas (descoberta, ideação, modelação e implantação). Nesse fluxo, o SEBRAE utiliza expressões sedutoras e atrativas (transformar sonhos e propósitos; poder das ideias e da criatividade), bem como da imagem do foguete (aquele que desbrava mundos desconhecidos) para levar os indivíduos a adotarem a cultura empreendedora.

Segundo o SEBRAE, essas etapas podem ser utilizadas para elaboração e aplicação de produtos e organização de portfólios. Essas etapas, são extraídas acriticamente da proposta da Pedagogia Histórico-Crítica (PHC), como Dias (2019) nos apresenta em sua análise. A etapa da "Descoberta", se relacionaria a prática social inicial. Já etapa de "Ideação", seria a problematização. A etapa de "Modelagem", a instrumentalização e a etapa de "Implementação", seria a prática social final. Chamamos a atenção e enfatizamos que a apropriação que o SEBRAE faz da PHC é incompatível com a visão de mundo, de educação e de sujeito que a PHC traz em suas concepções. Neste sentido, essa apropriação do SEBRAE produz uma forma mecanizada para relativizar situações e conteúdos utilizados na resolução de problemas no plano individual, ao mesmo tempo que busca atender o mercado de trabalho.

$\mathrm{Na}$ seção "Oferta de conteúdos de empreendedorismo pelo Sebrae" procura-se mostrar através de resultados do PISA que o modelo de educação do Brasil não vem funcionando. Neste sentido, o SEBRAE se mostra aberto a contribuir com os órgãos gestores da educação para organizar e oferecer itinerários formativos com foco no eixo empreendedorismo. Nesta relação, ele compartilharia produtos de educação empreendedora, seja para a modalidade presencial ou a distância, bem como no desenvolvimento de novos produtos e objetos de aprendizagem (como fez com a rede estadual do Rio de Janeiro), para atender a educação pública e privada.

Essa desqualificação da escola pública através das avaliações externas, 
O bloco hegemônico investe na desqualificação da escola pública - contando, inclusive, com a adesão desapercebida de setores populares - para, em seguida, apresentar a solução: entregar a escola à competência administrativa dos senhores de negócios e a seus institutos. A este processo denominamos neste trabalho "sequestro da escola". O espaço moral para que a escola seja sequestrada pelo capital consiste em constatar-lhe a falência, associando-a à democratização. Eis o caráter moral do sequestro: se, com o movimento de democratização e autonomia, a escola pública chegou ao ponto de indigência que todos percebem, a solução é entregá-la ao capital.

Na seção "O Sebrae no Novo Ensino Médio", o SEBRAE vai reforça a oportunidade de se implementar a educação empreendedora através dos itinerários formativos e eixos estruturantes com a aprovação da contrarreforma do Ensino Médio de 2017, das atualizações das DCNEM de 2018 e da BNCC. Essas mudanças na legislação educacional possibilitou as instituições públicas e privadas a estabelecerem "parcerias" com instituições de ensino ou organizações, entre elas o SEBRAE. Neste sentido, o SEBRAE se apresenta como um "parceiro" em potencial para que a cultura empreendedora faça parte dos itinerários e eixos estruturantes dessas instituições parceiras.

Além disso, o SEBRAE apresenta as variadas opções metodológicas que as escolas podem adotar a partir da sua capacitação para desenvolver os conteúdos do empreendedorismo.

Aprendizagem ativa (utilização de objetos de aprendizagem e de produtos em diferentes formatos, modalidades e canais); Aprendizagem baseada em projetos (em que há um processo claro de produção de ideias e um produto final específico, estimulando o financiamento coletivo ou outras formas de sustentabilidade das ações). Aprendizagem experimental (levantamento de ideias, desenvolvimento de modelagem e prototipagem de produtos e serviços que atendam alguma necessidade); Atividades no exterior da sala de aula ou da escola (que visem o contato dos alunos com a comunidade local ou com empresas e a utilização de ideias inovadoras para criar soluções que permitam resolver problemas locais/na comunidade ou projetos criados por empresas ou organizações na comunidade para resolver um problema que enfrentam no trabalho). Aprendizagem por meio de criação de proposta de miniempresa ou empresa estudantil (ter uma ideia para um empreendimento comercial ou social, criá-lo e dirigi-lo durante um determinado período de tempo); Eventos presenciais e/ou remotos envolvendo grandes públicos (congressos, seminários, encontros, talk show, webinars, etc) (SEBRAE, 2020, p. 42).

Como podemos notar, são as metodologias ligadas ao lema "aprender a aprender" ${ }^{5}$, que se voltam para a adaptação dos indivíduos a lógica do mercado e a

5 O lema "aprender a aprender", "sintetiza uma concepção educacional voltada para a formação da capacidade adaptativa dos indivíduos (DUARTE, 2001, p.38)". 
Programa de Pós-graduação em Educação, Universidade Federal do Ceará

Fortaleza-CE-Brasil

sociabilidade burguesa. Essas metodologias e os conteúdos da educação empreendedora podem ser adaptadas de acordo com as necessidades de cada instituição escolar e seus níveis de ensino, podendo ser oferecidas oficinas rápidas, presenciais ou remotas. Assim sendo, o SEBRAE se coloca "como parceiro das Secretarias de Educação dos estados e municípios brasileiros para, juntos, definir políticas de apoio a esse público, o Sebrae amplia o seu atendimento e consolida a sua função social (SEBRAE, 2020, p. 42)".

Para finalizar, na seção "Finalizando: A Missão Sebrae de Empreendedorismo", o documento reforça que a educação empreendedora do SEBRAE se pauta nos quatro pilares da educação da UNESCO, estando de acordo "com documentos oficiais produzidos pelos órgãos normatizadores do ensino no Brasil e refletem o desenvolvimento de competências propostos por organismos internacionais, nos quais a Educação Empreendedora do Sebrae também se inspira (p.43)", bem como sua missão "é fomentar o empreendedorismo e contribuir para a construção de uma cultura empreendedora no país (SEBRAE, 2020, p. 43)".

Nota-se que o próprio SEBRAE reconhece a influência dos organismos internacionais nas formulações educacionais brasileiras, entrando em conformidade com elas, reproduzindo em seu projeto de "educação empreendedora" os interesses dos países de capitalismo central que controlam esses organismos e representam os interesses da burguesia e não da classe trabalhadora.

\section{Considerações finais}

Ao longo da análise apresentada nesse artigo, podemos constatar que 0 SEBRAE tem atuado para se consolidar como principal difusor da cultura empreendedora no Brasil através de seu projeto de "educação empreendedora". Destaca-se a ofensiva dessa organização sobre as instituições educacionais brasileiras, sejam públicas ou privadas, após a inserção do empreendedorismo como eixo estruturante para o ensino médio e seus itinerários formativos, e principalmente com a publicação do documento analisado.

Ressaltamos que o SEBRAE utiliza de diversas estratégias de convencimento para difundir a cultura empreendedora dentro dessas instituições, utilizando, desde sua experiência com o empreendedorismo junto as micro e pequenas empresas e com a "educação empreendedora", justificando sua expertise, 
Programa de Pós-graduação em Educação, Universidade Federal do Ceará

Fortaleza-CE-Brasil

bem como, pelo seu alinhamento as normatizações educacionais internacionais, que são balizadoras das políticas educacionais nacionais, mantendo assim a sua continuidade. Além disso, neste contexto de pandemia do COVID-19, o SEBRAE procura sustentar que as competências empreendedoras são fundamentais para enfrentar as consequências da crise em curso, bem como as instabilidades e incertezas decorrentes da 40 Revolução Industrial, sem mencionar que essas consequências e instabilidades são resultantes do próprio sistema capitalista. Outro ponto a se destacar em nossa análise sobre a atuação do SEBRAE, se volta para o discurso da capacidade de adaptação da "educação empreendedora" as necessidades individuais de cada instituição escolar, assim como de cada indivíduo e seu projeto de vida, trazendo para o plano individual, um projeto que busca a universalização da cultura empreendedora para a reprodução ampliada do modo de produção capitalista e da sociabilidade burguesa.

Concluímos então que o documento analisado "Empreendedorismo no currículo do Ensino Médio" produzido pelo SEBRAE tem uma intencionalidade explicita de colocar o SEBRAE com o principal "parceiro" para desenvolver o empreendedorismo no ensino médio das instituições educacionais do país, e disseminar a cultura empreendedora para todos os indivíduos, sejam eles gestores, professores ou estudantes. Assim sendo, o SEBRAE teria a capacidade de expandir suas concepções liberais e neoliberais a todos os futuros trabalhadores e cidadãos, de modo a moldar uma nova forma de ser, agir e pensar na sociedade.

Além disso, constatamos que as ações desempenhadas pelo SEBRAE na educação formal e informal tem a intenção de difundir a cultura empreendedora e a concepção empresarial de mundo, ao incentivar o exercício da veia empresarial dos indivíduos desde os anos iniciais da escola, como nos alerta Dias (2018) e Castro (2019), para que esse indivíduo assuma-se enquanto ele próprio como uma empresa, tornando-se sócio majoritário de si, como assevera Dias (2019) em sua Tese.

\section{Referências Bibliográficas}

BRASIL. Lei № 13.415, de 16 de fevereiro de 2017. Brasília: Diário Oficial da União, seção 1, ํo35, 2017a. Disponível em: http://prograd.uesb.br/proreitorias/prograd/wpcontent/uploads/lei da reforma do ensino medio.pdf Acesso em: 21 de jan. 2021.

BRASIL. RESOLUÇÃO № 3, DE 21 DE NOVEMBRO DE 2018. Atualiza as Diretrizes Curriculares Nacionais para o Ensino Médio. Brasília: Ministério da Educação, 2018a. 
Programa de Pós-graduação em Educação, Universidade Federal do Ceará

Fortaleza-CE-Brasil

\begin{tabular}{lll}
\hline Disponível & em: & http://www.in.gov.br/materia/- \\
lasset publisher/Kujrw0TZC2Mb/content/id/51281622 & Acesso em: 20 jan. 2021.
\end{tabular}

BRASIL. Base Nacional Comum Curricular - BNCC, Ensino Médio. Brasília, 2018b. Disponível em: http://portal.mec.gov.br/conselho-nacional-de-educacao/basenacional-comum-curricular-bncc-etapa-ensino-medio Acesso em: 12 de jan. 2021.

CASTRO. Luiger Franco de. "APRENDER A EMPREENDER”: o projeto de educação do SEBRAE para a educação básica pública. Dissertação de Mestrado em Educação. Universidade Federal de Juiz de Fora, Juiz de Fora - MG., 2019. Disponível em: https://repositorio.ufjf.br/jspui/handle/ufjf/10264 Acesso em: 6 jan. 2021.

DIAS, Graziany Penna. Empreendedorismo, educação e sociabilidade: a radicalização do indivíduo como sócio majoritário de si. Tese de Doutorado em Educação Juiz de Fora - MG. Universidade Federal de Juiz de Fora, 2019.. Disponível em: http://repositorio.ufjf.br:8080/jspui/handle/ufff/10755 Acesso em: 22 de jan. 2021.

DIAS, Vanessa Tavares. A "miséria" da educação: análise de um manual de "empreendedorismo" do SEBRAE para professores do ensino fundamental. Século XXI, Revista de Ciências Sociais, v.8, no 1, p.379-416, jan.jun. 2018. Disponível em: https://periodicos.ufsm.br/seculoxxi/article/view/35678 Acesso em: 6 jan. 2021.

DELORS, Jacques. Educação: um tesouro a descobrir. Relatório para a UNESCO da Comissão Internacional sobre Educação para o século XXI. São Paulo: Cortez, 1998. DUARTE, Newton. Os conteúdos escolares e a ressurreição dos mortos: contribuição à teoria histórico-crítica do currículo. Campinas: Autores Associados, 2016 (Coleção educação contemporânea).

GAMBOA, Silvio Ancízar Sanchez. A dialética na pesquisa em educação: elementos de contexto. In: FAZENDA, Ivani (org). Metodologia da pesquisa educacional. São Paulo: Cortez, 2000. p. 91-116.

GRAMSCI, Antonio. O leitor de Gramsci: escritos escolhidos 1916-1935. Rio de Janeiro: Civilização Brasileira, 2011.

GRAMSCI, Antonio. Cadernos do cárcere. Volume 3: Maquiavel. Notas sobre o Estado e a Política. 6d. Rio de Janeiro: Civilização Brasileira, 2014.

KOSIK, Karel. Dialética do Concreto. Rio de Janeiro: Paz e Terra, 1976.

MARTINS, André Silva. A direita para o social: a educação da sociabilidade no Brasil contemporâneo. Juiz de Fora: Editora UFJF, 2009.

MARTINS, André Silva; SOUZA, Camila. Azevedo.; PINA, Leonardo Docena. Empresas sociais e a privatização de novo tipo da educação básica: um estudo sobre a relação público-privada em cidades de Minas Gerais-Brasil. Arquivos Analíticos de Políticas Educativas, v. 28, n. 183, dez. 2020. Disponível em: https://dialnet.unirioja.es/servlet/articulo?codigo=7768076 Acesso em: 11 jan. 2021 

currículo mínimo de educação física do estado do Rio de Janeiro: da elaboração à implementação. Dissertação de Mestrado em Educação. Universidade Federal de Juiz de Fora. Juiz de Fora-MG, 2019. Disponível em: https://repositorio.ufjf.br/jspui/bitstream/ufjf/9322/1/ramonmendesdacostamagalhaes. pdf Acesso em: 22 de Fev. 2020.

POULANTZAS, Nicos. O Estado, o poder, o socialismo.1ed. São Paulo: Paz e Terra, 2015.

PREALC. Programa de Reforma Educativa da América Latina e Caribe. PRELAC, uma trajetória para Educação para a Todos. Panorama Socioeducacional: cinco visões sugestivas para a América Latina e Caribe. Revista PRELAC. Santiago: Escritório Regional de Educação da Unesco para a América Latina e Caribe. Ano 1, n. 0, ago. 2004.

SANTOS, Aparecida de Fátima Tiradentes dos. Pedagogia do mercado: neoliberalismo, trabalho e educação no século XXI. Rio de Janeiro: Ibis Libris, 2012.

SEBRAE, Serviço Brasileiro de Apoio às Micro e Pequenas Empresas. Empreendedorismo no currículo escolar do ensino médio. Brasília-DF. 2020.

SEBRAE. Serviço Brasileiro de Apoio às Micro e Pequenas Empresas. Quem Somos. S/d1, online. Disponível em: http://www.sebrae.com.br/sites/PortalSebrae/canais adicionais/conheca quemsomo

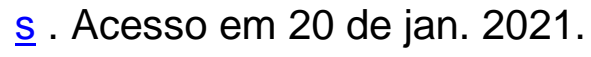

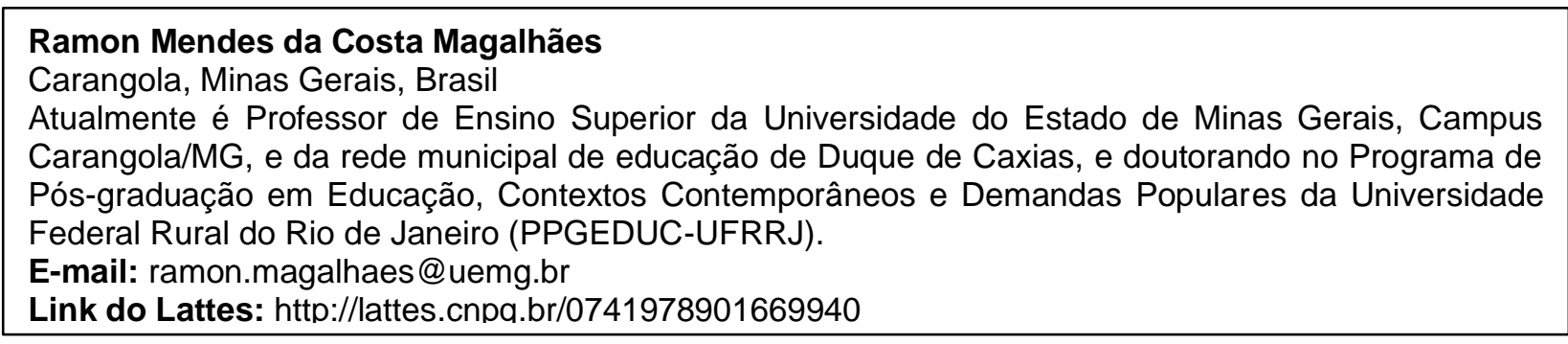

\section{Rodrigo de Azevedo Cruz}

Nova Iguaçu, Rio de Janeiro, Brasil

Professor Adjunto do Departamento Educação e Sociedade (DES) e do Programa de Pós-Graduação em Educação, Contextos Contemporâneos e Demandas Populares (PPGEduc) na Universidade Federal Rural do Rio de Janeiro (UFRRJ). Mestre e doutor em Educação pelo Programa de Pósgraduação em Educação (PPGE) da Universidade Federal do Rio de Janeiro (UFRJ) com apoio da Coordenação de Aperfeiçoamento de Pessoal do Ensino Superior (CAPES). Bacharel e licenciado em História pela Universidade Federal Fluminense (UFF). Líder do grupo de pesquisa Laboratório de Investigação em Estado, Poder e Educação (LIEPE). Membro filiado à International Gramsci Society (IGS) e à Red Latinoamericana y Caribña de Estudos Gramscianos. Coordenador da coluna Tubarões da Educação no portal Esquerda On Line.

E-mail: rodrigo1281@yahoo.com.br

Link do Lattes: http://lattes.cnpq.br/1913716021055272 


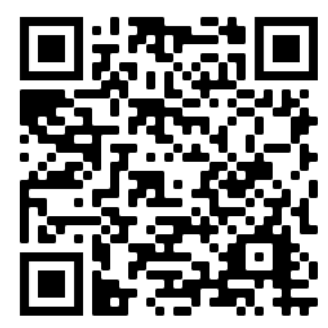

Q.Code

\section{Editores-Responsáveis}

Dr. Enéas de Araújo Arrais Neto, Universidade Federal do Ceará, UFC, Ceará, Brasil Dr. Sebastien Pesce, Universidade de Orléans, França 